\title{
Article
}

\section{Finding Stable QTL for Plant Height in Super Hybrid Rice}

\author{
Huali Yang ${ }^{1}$, Qinqin Yang ${ }^{1}$, Yiwei Kang ${ }^{1}$, Miao Zhang ${ }^{1}$, Xiaodeng Zhan ${ }^{1}$, Liyong Cao ${ }^{1,2}$, Shihua Cheng ${ }^{1}$, \\ Weixun $\mathrm{Wu}^{1}{ }^{1}$ and Yingxin Zhang ${ }^{1, *}$
}

1 State Key Laboratory of Rice Biology and Chinese National Center for Rice Improvement, China National Rice Research Institute, Hangzhou 311401, China; yanghuali1125@163.com (H.Y.); yqq13290055214@163.com (Q.Y.); 13067763611@163.com (Y.K.); zhangmiao9605@163.com (M.Z.); zhanxiaodeng@caas.cn (X.Z.); caoliyong@caas.cn (L.C.); chengshihua@caas.cn (S.C.); wuweixun@caas.cn (W.W.)

2 Northern Center of China National Rice Research Institute, Jiamusi 155100, China

* Correspondence: zhangyingxin@caas.cn; Tel.: +86-571-6637-0218

check for updates

Citation: Yang, H.; Yang, Q.; Kang, Y.; Zhang, M.; Zhan, X.; Cao, L.; Cheng, S.; Wu, W.; Zhang, Y. Finding Stable QTL for Plant Height in Super Hybrid Rice. Agriculture 2022, 12, 165. https://doi.org/10.3390/ agriculture12020165

Academic Editor: Nacer Bellaloui

Received: 8 December 2021

Accepted: 14 January 2022

Published: 24 January 2022

Publisher's Note: MDPI stays neutral with regard to jurisdictional claims in published maps and institutional affiliations.

Copyright: (C) 2022 by the authors. Licensee MDPI, Basel, Switzerland. This article is an open access article distributed under the terms and conditions of the Creative Commons Attribution (CC BY) license (https:// creativecommons.org/licenses/by/ $4.0 /)$.

\begin{abstract}
Plant height $(\mathrm{PH})$ is one of the most important agronomic traits determining plant architecture in rice. To investigate the genetic basis of plant height in the high-yielding hybrid rice variety Nei2You No.6, recombinant inbred sister lines (RISLs) were used to map quantitative trait loci (QTL) over four years. A total of 19 minor/medium-effect QTLs were mapped on eleven chromosomes except chromosome 10, totally explaining 44.61-51.15\% phenotypic variance in four environments. Among these, $q P H-1 a, q P H-1 b, q P H-2 b, q P H-3 b, q P H-6$, and $q P H-7 b$ were repeatedly detected over four years. Among these, the $q P H-6$ was mapped to an interval of $22.11-29.41 \mathrm{Mb}$ on chromosome $6 \mathrm{~L}$, which showed the highest phenotypic variation explained (PVE) of 10.22-14.05\% and additive effect of 3.45-4.63. Subsequently, evaluation of near isogenic lines (NILs) showed that the $q P H-6$ allele from the restorer line (R8006) could positively regulate plant height, resulting in an $18.50 \%$ increase in grain yield. These results offered a basis for further mapping of $q P H-6$ and molecular breeding in improving plant architecture in rice.
\end{abstract}

Keywords: Oryza sativa L.; plant height; quantitative trait loci; $q P H-6$

\section{Introduction}

As a staple food feeding over half of the world's population, rice (Oryza sativa L.) plays a vital role in food security in rice-growing countries, especially in Asia [1]. Plant height $(\mathrm{PH})$ is an important agronomic trait related to biomass and lodging resistance [2]. Rice yield is composed of biomass and harvest index. The "Green Revolution" led to a huge increase in rice yield by reducing plant height and enhancing harvest index in the 1950s. However, as the potential of the harvest index is exhausted (approximately 54.5\%), increasing biomass is becoming the principal strategy to further improve rice yield [3]. The breeding of super rice is the latest trend in enhancing plant height and is becoming one of the main strategies in improving rice yield [4]. Hence, it is of great significance to investigate plant height genes for rice breeding.

Rice plant height is a complex agronomic trait influenced by the environment and is genetically controlled by quantitative trait loci (QTL). QTL mapping is one of the most efficient strategies for excavating PH-related genes in rice [5]. Hundreds of PH QTLs have been mapped on all 12 chromosomes in rice, mainly distributed on chromosomes 1, 3, and 4 (www.gramene.org/, accessed on 13 January 2022). However, only a few major loci for plant height have been isolated, such as the "Green Revolution" genes sd1/OsGA20ox2 [6,7], OsGA20ox1, and IPA1 [8,9]. OsGA20ox2 and OsGA20ox1 participate in gibberellin synthesis, while IPA1 changes rice plant architecture and enhances grain yield by regulating OsmiR156 [10]. On the other hand, pleiotropic genes controlling grain number, plant height, and heading date have been cloned, such as Ghd7, Ghd7.1, Ghd8, and Ghd2 [11-14]. Recently, the qSBM1 was reported to increase plant height and biomass 
aboveground, resulting in enhanced grain number per panicle, grain yield per plant, and nitrogen efficiency [15]. In view of the limited number of cloned loci, investigating new stable plant height QTLs is a pressing demand in rice. Additionally, environmental instability is the major obstacle for QTL mapping; therefore, it is necessary to experiment in multiple environments.

In this study, recombinant inbred sister lines (RISLs) derived from hybrid Nei2You No.6 were used to map QTLs for plant height in hybrid rice. As a result, a total of 19 QTLs were mapped, among which $q P H-1 a, q P H-1 b, q P H-2 b, q P H-3 b, q P H-6$, and $q P H-7 b$ were detected to exhibit stable effects over four years. The $q P H-6$ with the largest effect was subsequently proved to enhance plant height and yield by developing near-isogenic lines (NILs). These results offer useful information for improving plant height and grain yield in rice molecular breeding.

\section{Materials and Methods}

\subsection{Materials and Traits Measurements}

Nei2You No.6 is a high-yielding three-line hybrid indica variety bred by the China National Rice Research Institute (http:/ / www.ricedata.cn/variety/superice.htm, accessed on 13 January 2022). The RISL population $\left(\mathrm{F}_{15}\right)$ was developed from a cross between the maintainer Nei2B and the restorer Zhonghui8006 (R8006), consisting of 386 lines with 3203 Bin markers [16]. A total of 386 lines consisted of 193 pairs, with two randomly selected individuals as a pair in the $\mathrm{F}_{7}$ progeny. The genetic variation between the paired lines at the target interval allowed us to obtain residual heterozygous lines (RHLs) by tracing the previous generation (Figure 1). For QTL mapping, parental lines and RISLs were planted in Fuyang (FY, $119^{\circ} 57^{\prime}$ E, 30 $30^{\circ}$ N), Zhejiang Province from 2015 to 2018. All trials were performed with a completely randomized block design with two replications. Approximately 25 days after germination, 16 plants from each line were transplanted into two rows with a spacing of $21 \mathrm{~cm} \times 18 \mathrm{~cm}$ in early June. Field management followed conventional practices. At maturity, the plant height of six individuals from each RISL line was measured manually with a straightedge. For the NILs, at least eight individuals from the inner portion of each line were collected to evaluate their plant heights, heading dates, and yield traits. For the phenotype of the plant yield, sun-dried threshed seed was evaluated with an automatic seed examination system (Wanshen Detection Technology Co., Ltd., Hangzhou, China).

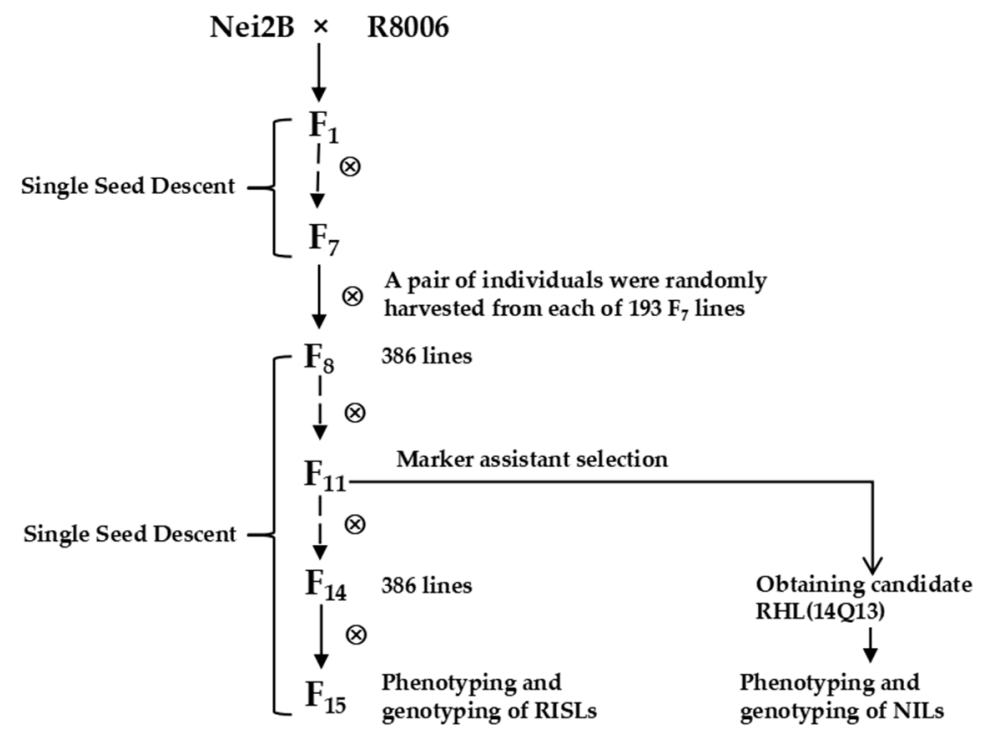

Figure 1. The construction process of recombination inbred sister lines. 


\subsection{QTL Mapping and Statistical Analysis}

Based on a 1000-permutation test at a threshold value of LOD $\geq 2.5$, additive QTL was analyzed with the composite interval mapping (CIM) function in WinQTLCart 2.5 software [17]. With a search step of $1 \mathrm{cM}$, the percentage of phenotypic variation explained (PVE, \%), and the additive effects were estimated at a 95\% confidence level [18,19]. Nomenclature of QTL followed the recommendations of McCouch and Cgsnl [20]. For parents and RISLs, all statistical analyses were carried out using Microsoft Excel and Prism 8 software (GraphPad). Frequency distribution of plant height was drawn in Microsoft Excel 2010 to identify the pattern of variation of plant height within the population. For QTL validation, data of the RISLs were compared using Student's $t$-tests.

\subsection{Developing of NILs for $q \mathrm{PH}-6$}

Firstly, the corresponding paired lines $(\mathrm{Q} 13$ and $\mathrm{Q} 14)$ in the $\mathrm{F}_{15}$ generation with minimal genomic differences except target $q P H-6$ were selected by scanning the Bin map. Tracing them to the ancestors of Q13 and Q14, a residual heterozygote line, namely 14Q13, was selected from the $\mathrm{F}_{11}$ generation of Nei2B/R8006, which harbored heterozygous $q P H-6$ allele and was used for developing NILs. During this process, 512 markers from the universal core map [21] were utilized in the marker-assisted selection (MAS) process. In the $\mathrm{F}_{15}$ generation, a pair of NILs named $q P H 6-\mathrm{N}$ and $q P H 6-\mathrm{R}$ were obtained with the $q P H-6$ allele from Nei2B and R8006, respectively. The NILs, $q P H 6-N$ and $q P H 6-R$, were cultivated in Fuyang for phenotypic evaluating in the summer of 2019.

\section{Results}

\subsection{Phenotypic Analysis of Parents and RISLs}

The Nei2You No.6 is a three-line hybrid variety suitable for planting in the middle and lower reaches of the Yangtze River. To investigate the genetic basis of plant height for Nei2You No.6, the experiments were conducted in Hangzhou, Zhejiang Province over four consecutive years. Over the four years, the parental lines Nei2B, R8006 and $\mathrm{F}_{1}$ (Nei2You No.6) showed stable plant heights of approximately $94.0 \mathrm{~cm}, 104.0 \mathrm{~cm}$, and $113.0 \mathrm{~cm}$, respectively, indicating the heterosis of plant height in Nei2You No.6. (Table 1). Wide variations and transgressive segregation were found in the RISLs for plant height in all four years (Figure 2, Table 1). Additionally, over four years, with the skewness from -1 to 1 , the plant height showed normal distribution in the RISLs (Figure 2). These results suggested that the plant height in Nei2You No.6 was genetically controlled by quantitative trait loci.

Table 1. The phenotypic performance of the parental lines and recombinant inbred sister lines (RISL) population in all four years.

\begin{tabular}{cccccccc}
\hline Year & Nei2B & R8006 & F $_{\mathbf{1}}$ & RISLs' Mean $^{\prime}$ & RISLs' Range & Kurtosis & Skewness \\
\hline 2015 & $95.0 \pm 3.97^{\mathrm{a}}$ & $104.8 \pm 2.90^{\mathrm{b}}$ & $113.2 \pm 2.59^{\mathrm{c}}$ & $99.3 \pm 11.11$ & $67.8-149.0$ & 1.69 & 0.50 \\
2016 & $93.9 \pm 1.90^{\mathrm{a}}$ & $104.1 \pm 2.93^{\mathrm{b}}$ & $113.4 \pm 3.97^{\mathrm{c}}$ & $99.2 \pm 10.96$ & $63.6-147.0$ & 1.54 & 0.49 \\
2017 & $93.0 \pm 4.15^{\mathrm{a}}$ & $105.0 \pm 2.24^{\mathrm{b}}$ & $113.9 \pm 2.67^{\mathrm{c}}$ & $100.3 \pm 10.75$ & $62.2-152.6$ & 1.96 & 0.44 \\
2018 & $94.0 \pm 3.64^{\mathrm{a}}$ & $104.1 \pm 2.39^{\mathrm{b}}$ & $114.2 \pm 1.79^{\mathrm{c}}$ & $101.3 \pm 10.28$ & $65.0-155.3$ & 2.10 & 0.39 \\
\hline
\end{tabular}

a, b, c Means with superscript letters within each column indicate significant difference at $5 \%$ level via Duncan test for multiple comparisons.

\subsection{Identification of QTLs for Plant Height in the RISL Population}

As a result of QTL mapping, a total of 19 QTLs for plant height were detected in the RISLs in four years, located on all the chromosomes except chromosome 10 (Figure 3, Tables 2 and 3). Specifically, there were 12,13, 12, and 11 QTLs detected in 2015, 2016, 2017, and 2018, respectively. In the four different environments, the detected QTLs explained $44.61-51.15 \%$ of the total phenotypic variation observed. With a LOD value of $2.51-15.30$, each QTL showed a PVE of 2.08-14.05\% and additive effects of 1.68-4.63, indicating the 
medium/minor effect for plant height in Nei2You No.6. Notably, 12 QTLs were inherited from R8006 and 7 from Nei2B, showing the abundance of positive plant-height factors in the restorer line. Six loci $(q P H-1 a, q P H-1 b, q P H-2 b, q P H-3 b, q P H-6$, and $q P H-7 b)$ were repeatedly detected over four consecutive years. The details are as follows.

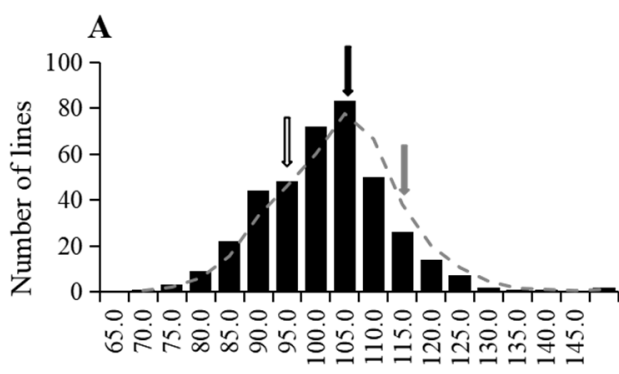

Plant height $(\mathrm{cm})$

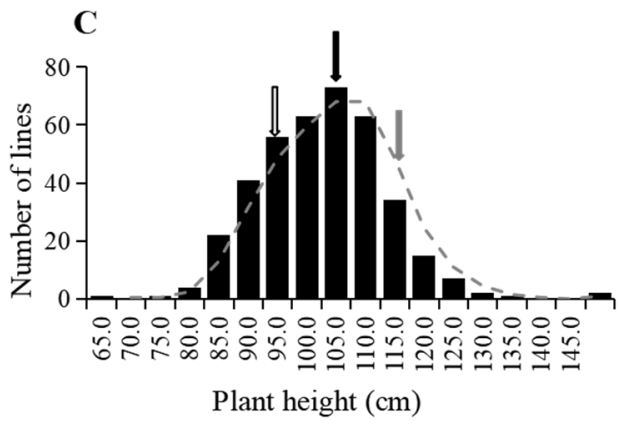

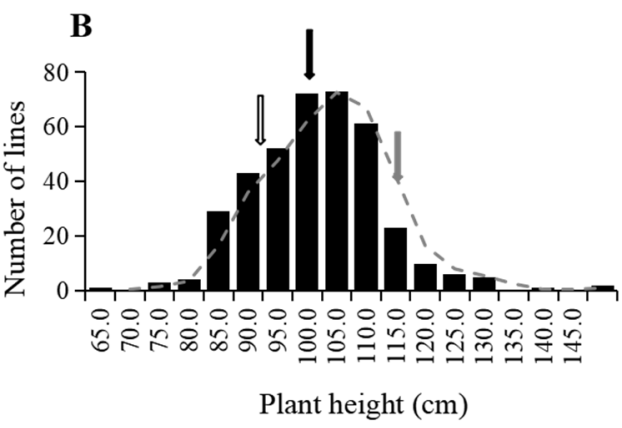

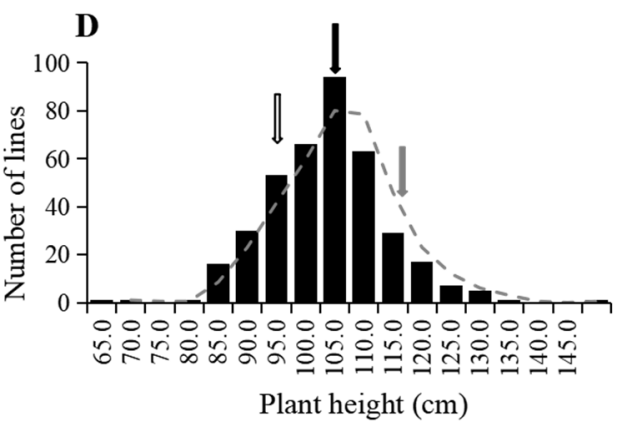

Figure 2. Phenotypic distribution of plant height in parental lines and RISLs in four environments. White, black, and gray arrows indicate Nei2B, R8006, and $F_{1}$, respectively. (A-D) Years 2015, 2016, 2017, and 2018, respectively.

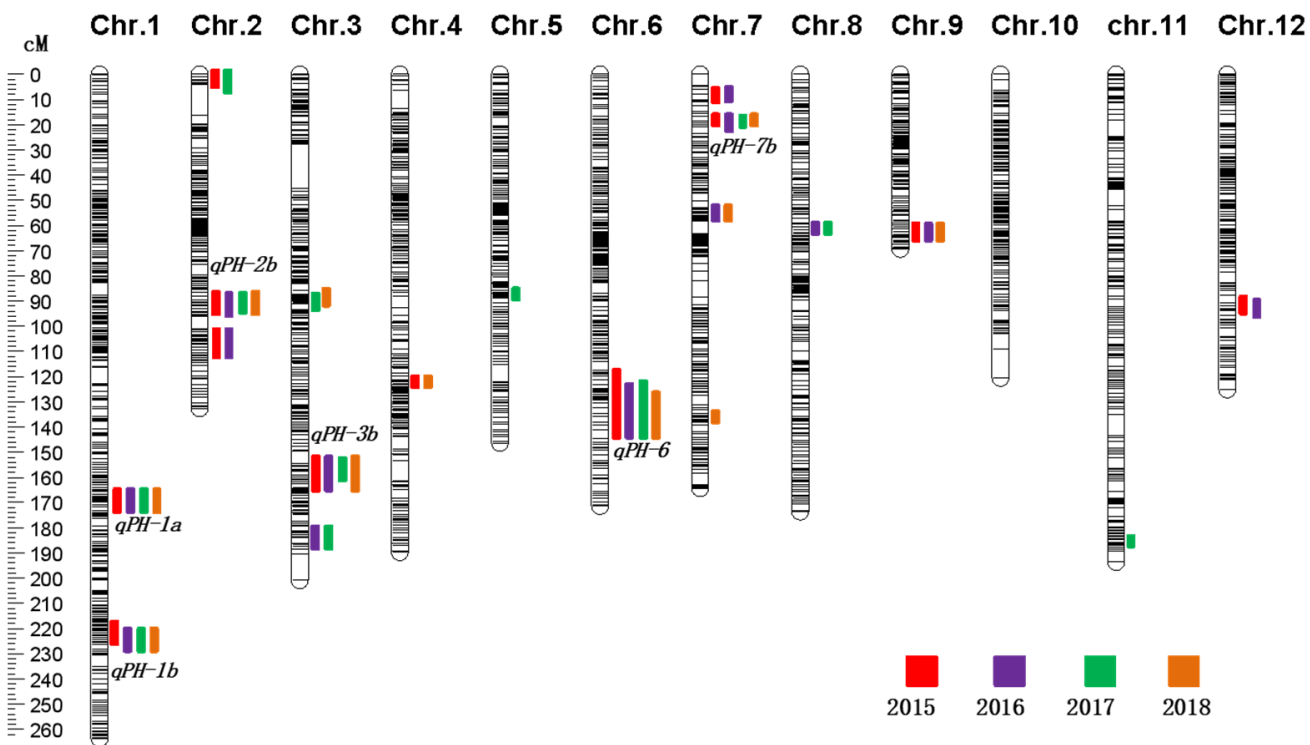

Figure 3. Genetic positions of detected QTLs for plant height in RISLs over four years. The scale on the left indicates map distance in centimorgans (cM). The black bands on each chromosome indicate the Bin markers. Graphics with different colors indicate the different environments of detected QTLs. Stably detected QTLs are labeled with names. 
Table 2. Information of stably detected quantitative trait loci (QTL) for plant height in the recombinant inbred sister lines (RISL) population across four environments.

\begin{tabular}{|c|c|c|c|c|c|c|c|c|}
\hline QTL & Chr. & Peak Bin & Flanking Marker & Interval $(\mathbf{M b})^{a}$ & LOD $^{b}$ & $\operatorname{PVE}(\%)^{c}$ & Add $^{d}$ & Year \\
\hline \multirow[t]{4}{*}{$q P H-1 a$} & 1 & $\operatorname{Bin} 272$ & Bin263-274 & $27.51-28.61$ & 3.15 & 2.58 & 2.02 & 2015 \\
\hline & & $\operatorname{Bin} 273$ & Bin263-274 & $27.51-28.61$ & 2.68 & 2.18 & 1.83 & 2016 \\
\hline & & $\operatorname{Bin} 273$ & Bin263-274 & $27.51-28.61$ & 2.58 & 2.13 & 1.78 & 2017 \\
\hline & & $\operatorname{Bin} 273$ & Bin263-274 & $27.51-28.61$ & 2.96 & 2.31 & 1.68 & 2018 \\
\hline \multirow[t]{4}{*}{$q P H-1 b$} & 1 & $\operatorname{Bin} 387$ & Bin367-410 & $38.51-43.31$ & 3.14 & 2.61 & 1.99 & 2015 \\
\hline & & Bin393 & Bin370-396 & $38.81-41.51$ & 3.30 & 2.80 & 2.04 & 2016 \\
\hline & & Bin393 & Bin370-396 & $38.81-41.51$ & 2.89 & 2.49 & 1.90 & 2017 \\
\hline & & Bin392 & Bin370-396 & $38.81-41.51$ & 2.70 & 2.12 & 1.58 & 2018 \\
\hline \multirow[t]{4}{*}{$q P H-2 b$} & 2 & Bin675 & Bin662-690 & $34.01-36.81$ & 5.15 & 4.45 & 2.58 & 2015 \\
\hline & & Bin676 & Bin666-690 & $34.41-36.81$ & 4.26 & 3.62 & 2.30 & 2016 \\
\hline & & Bin675 & Bin666-682 & $34.41-36.01$ & 5.12 & 4.43 & 2.51 & 2017 \\
\hline & & Bin675 & Bin662-690 & $34.01-36.81$ & 5.28 & 4.37 & 2.24 & 2018 \\
\hline \multirow[t]{4}{*}{$q P H-3 b$} & 3 & Bin957 & Bin941-998 & $32.11-37.81$ & 8.25 & 7.25 & 3.34 & 2015 \\
\hline & & Bin955 & Bin941-998 & $32.11-37.81$ & 7.03 & 6.36 & 3.10 & 2016 \\
\hline & & Bin956 & Bin941-960 & $32.11-34.01$ & 5.12 & 4.43 & 2.51 & 2017 \\
\hline & & Bin955 & Bin941-998 & $32.11-37.81$ & 5.28 & 4.37 & 2.24 & 2018 \\
\hline \multirow[t]{4}{*}{$q P H-6$} & 6 & Bin1843 & Bin1786-1858 & $22.11-29.41$ & 15.30 & 14.05 & 4.63 & 2015 \\
\hline & & $\operatorname{Bin} 1843$ & Bin1800-1858 & $23.51-29.41$ & 14.35 & 12.93 & 4.36 & 2016 \\
\hline & & Bin1843 & Bin1795-1858 & $23.01-29.41$ & 13.19 & 11.99 & 4.14 & 2017 \\
\hline & & $\operatorname{Bin} 1849$ & Bin1807-1858 & $24.21-29.41$ & 11.83 & 10.22 & 3.45 & 2018 \\
\hline \multirow[t]{4}{*}{$q P H-7 b$} & 7 & Bin1938 & Bin1935-1941 & $4.96-5.71$ & 4.93 & 4.24 & -2.64 & 2015 \\
\hline & & Bin1938 & Bin1935-1949 & $4.96-6.81$ & 5.30 & 4.51 & -2.69 & 2016 \\
\hline & & Bin1936 & Bin1935-1941 & $4.96-5.71$ & 4.06 & 3.51 & -2.32 & 2017 \\
\hline & & Bin1940 & Bin1935-1941 & $4.96-5.71$ & 4.69 & 4.05 & -2.28 & 2018 \\
\hline
\end{tabular}

a Physical position based on R498 genome (http:/ / www.mbkbase.org/R498/, accessed on 13 January 2022);

${ }^{b}$ average correlation threshold of QTL; ${ }^{c}$ phenotypic variation explained; ${ }^{d}$ additive effect.

$q P H-5, q P H-7 d$, and $q P H-11$ were detected in one year; $q P H-2 a, q P H-2 c, q P H-3 a, q P H-3 c$, $q P H-4, q P H-7 a, q P H-7 c$, and $q P H-12$ were detected in two years; $q P H-9$ was detected for three consecutive years; and $q P H-1 a, q P H-1 b, q P H-2 b, q P H-3 b, q P H-6$, and $q P H-7 b$ were repeatedly detected over four consecutive years. In detail, on chromosome $1 \mathrm{~L}$ (the long arm of chromosome 1), $q P H-1 a$ and $q P H-1 b$ were identified for plant height. Over four years, $q P H-1 a$ could explain $2.13-2.58 \%$ of the phenotypic variation, while $q P H-1 b$ was mapped with a PVE of $2.12-2.80 \%$ and additive effects of 1.58-2.04. With a LOD value of $4.26-5.28$, $q \mathrm{PH}-2 \mathrm{~b}$ was mapped on chromosome $2 \mathrm{~L}$ in four years, showing a PVE of $3.62-4.45 \%$ and additive effects of 2.24-2.58. The $q P H-3 b$ was delimited to an interval of $32.11-37.81 \mathrm{Mb}$ on chromosome $3 \mathrm{~L}$, showing $4.43-7.25 \%$ of the phenotypic variation. In particular, $q P H-6$ was detected in the interval of Bin1786-Bin 1858 on chromosome $6 \mathrm{~L}$, which could explain $10.22-14.05 \%$ of PVE with the largest effect over the four years. All the above five stable QTLs inherited the positive allele for plant height from the restorer line R8006. With the plant height-enhancing allele Nei2B, stable $q P H-7 b$ was mapped to an interval of $4.96-5.71 \mathrm{Mb}$ on the short arm of chromosome 7 with a PVE of 3.51-4.24\% and additive effects of 2.28-2.69. Additionally, there were 13 unstable QTLs detected in years 1, 2, and 3 with minor effects, located on chromosomes $2 \mathrm{~S}, 3 \mathrm{~L}, 4 \mathrm{~L}, 5 \mathrm{~L}, 7 \mathrm{~S}, 7 \mathrm{~L}, 8 \mathrm{~S}, 11 \mathrm{~L}$, and 12L (Figure 3 , Table 3). For instance, minor-effect $q P H-9$ was mapped on chromosome $9 \mathrm{~S}$ in the years 2016, 2017, and 2018 with the LOD peak at Bin2508.

\subsection{Verification of $q P H-6$}

Scanning the universal core map with 512 markers, 131 polymorphics were obtained between Nei2B and R8006, among which there were only eight markers (RM20352, RM5814, RM6289, RM6770, RM6659, RM1126, RM5590, and RM2851) that were heterozygous in the $\mathrm{F}_{11}$ line 14Q13. Subsequently, for developing NILs of $q P H-6$, the markers RM20352 and RM5814 on the long arm of chromosome 6 were used to select the foreground, while 
RM6289, RM6770, RM6659, RM1126, RM5590, and RM2851 were used for background scanning in the MAS process. As a result, a pair of NILs, namely $q P H 6-N$ and $q P H 6-R$, were obtained in the $\mathrm{F}_{15}$ progeny (Figure $4 \mathrm{~A}$ ). In detail, $q P H 6-\mathrm{N}$ and $q P H 6-R$ showed the same genomes, except two segments on chromosome $6 \mathrm{~L}$ and chromosome $12 \mathrm{~S}$ and the target $q$ PH6 located in the differential segment on the chromosome 6L flanked by RM20352 and RM5814. The NIL $q P H 6-R(104.77 \pm 2.00 \mathrm{~cm})$ showed an enhanced plant height that was $10.70 \%$ greater than that of $q P H 6-N(96.64 \pm 4.46 \mathrm{~cm})$, illustrating the stable existence of $q P H-6$ (Figure $4 \mathrm{~B}, \mathrm{E}$ ). Additionally, $q P H 6-\mathrm{R}$ had a higher yield than $q P H 6-N$. A total of 2.89 days later than $q P H 6-N$ in heading date, $q P H 6-R$ could increase the number of grains per panicle and grain yield per plant by $21.87 \%$ and $18.50 \%$, respectively (Figure $4 \mathrm{~F}-\mathrm{H}$ ). These results indicate that $q P H-6$ is a stable QTL for plant height with pleiotropic effects on multiple agronomic and yield traits.

Table 3. Information of unstable quantitative trait loci (QTL) for plant height in the recombinant inbred sister lines (RISL) population.

\begin{tabular}{|c|c|c|c|c|c|c|c|}
\hline QTL & Chr. & Peak Bin & Interval $(\mathbf{M b})^{a}$ & LOD $^{b}$ & $\operatorname{PVE}(\%)^{c}$ & Add $^{d}$ & Year \\
\hline \multirow[t]{2}{*}{$q P H-2 a$} & 2 & Bin443 & $2.31-2.41$ & 2.56 & 2.10 & 2.02 & 2015 \\
\hline & & Bin444 & $2.31-2.71$ & 3.00 & 2.47 & 1.83 & 2017 \\
\hline \multirow[t]{2}{*}{$q P H-2 c$} & 2 & Bin688 & $34.41-36.61$ & 2.83 & 2.50 & 1.78 & 2015 \\
\hline & & Bin688 & $34.41-36.61$ & 2.82 & 2.44 & 1.68 & 2016 \\
\hline \multirow[t]{2}{*}{$q P H-3 a$} & 3 & Bin820 & $17.01-17.61$ & 3.02 & 2.36 & 1.99 & 2018 \\
\hline & & Bin816 & $17.01-18.21$ & 3.02 & 2.52 & 2.04 & 2017 \\
\hline \multirow[t]{2}{*}{$q P H-3 c$} & 3 & Bin969 & $25.61-26.21$ & 4.00 & 3.63 & 1.90 & 2016 \\
\hline & & $\operatorname{Bin} 970$ & $25.61-26.21$ & 3.04 & 2.75 & 1.58 & 2017 \\
\hline \multirow[t]{2}{*}{$q P H-4$} & 4 & Bin1238 & $25.11-25.61$ & 2.73 & 2.38 & 2.58 & 2015 \\
\hline & & Bin1232 & $25.11-25.61$ & 2.68 & 2.10 & 2.30 & 2018 \\
\hline$q P H-5$ & 5 & Bin1521 & $24.81-25.21$ & 2.56 & 2.11 & 2.51 & 2016 \\
\hline \multirow[t]{2}{*}{$q P H-7 a$} & 7 & Bin1916 & $4.81-5.01$ & 3.17 & 2.77 & 2.24 & 2015 \\
\hline & & Bin1917 & $4.81-5.01$ & 3.24 & 2.80 & 3.34 & 2016 \\
\hline \multirow[t]{2}{*}{$q P H-7 c$} & 7 & Bin1960 & $9.01-9.31$ & 2.56 & 2.30 & 3.10 & 2016 \\
\hline & & Bin1983 & $9.01-9.31$ & 2.51 & 2.08 & 2.51 & 2018 \\
\hline$q P H-7 d$ & 7 & $\operatorname{Bin} 2121$ & $14.21-14.91$ & 5.03 & 4.15 & 2.24 & 2018 \\
\hline \multirow[t]{2}{*}{$q P H-8$} & 8 & Bin2230 & $9.66-10.26$ & 3.23 & 2.74 & 4.63 & 2016 \\
\hline & & Bin2230 & $9.66-10.26$ & 2.67 & 2.29 & 4.36 & 2017 \\
\hline \multirow[t]{3}{*}{$q P H-9$} & 9 & Bin 2508 & $18.11-18.31$ & 3.90 & 3.34 & 4.14 & 2016 \\
\hline & & Bin2508 & $18.11-18.31$ & 2.65 & 2.16 & 3.45 & 2017 \\
\hline & & Bin2508 & $18.11-18.31$ & 3.54 & 2.77 & -2.64 & 2018 \\
\hline$q P H-11$ & 11 & Bin 3022 & $30.91-31.41$ & 2.52 & 2.08 & -2.69 & 2017 \\
\hline \multirow[t]{2}{*}{$q P H-12$} & 12 & Bin3189 & $16.86-17.26$ & 2.72 & 2.23 & -2.32 & 2015 \\
\hline & & Bin3189 & $16.96-17.36$ & 3.33 & 2.69 & -2.28 & 2016 \\
\hline
\end{tabular}

a Physical position based on R498 genome (http:/ / www.mbkbase.org/R498/, accessed on 13 January 2022),

$\mathrm{b}$ average correlation threshold of QTL; ${ }^{\mathrm{c}}$ phenotypic variation explained; ${ }^{\mathrm{d}}$ additive effect. 
A
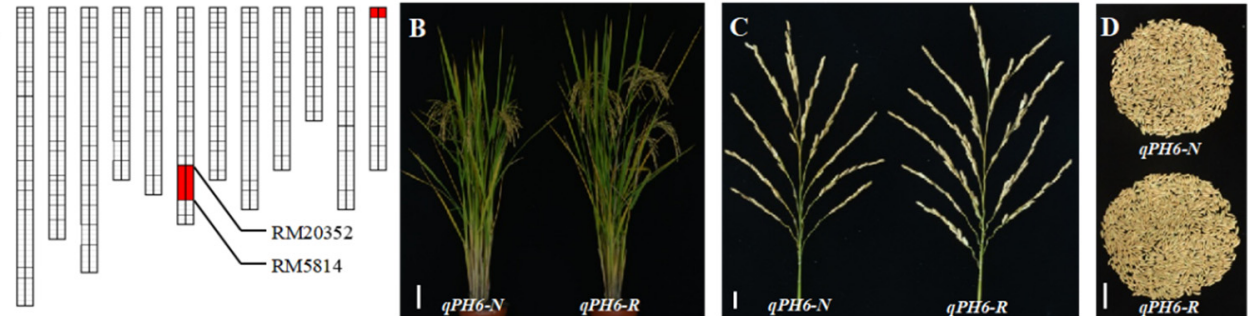

E

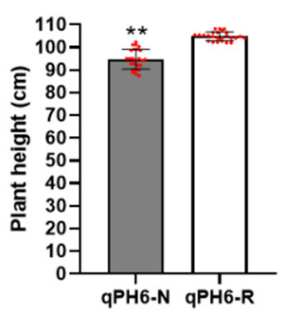

$\mathbf{F}$

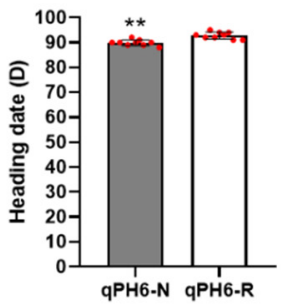

G

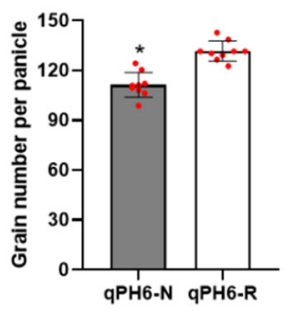

H

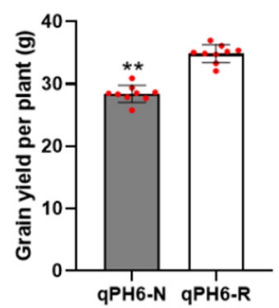

Figure 4. $q P H-6$ regulates plant height and grain yield. (A) Graphical genotype of NILs $q P H 6-N$ and $q P H 6-R$. The horizontal lines on each chromosome represent polymorphic markers. $q P H 6-N$ and $q P H 6-R$ share same and opposite genotypes in white and red color, respectively. (B) Plant height of NILs, Bar, $10 \mathrm{~cm}$. (C) Panicle phenotype, Bar, $1 \mathrm{~cm}$. (D) Phenotype of grain yield per plant, Bar, $2 \mathrm{~cm}$. (E-H) Comparison of plant height, heading date, grain number per panicle, and grain yield per plant between $q P H 6-N$ and $q P H 6-R$, respectively. The data are shown as mean \pm sd., ${ }^{*} p<0.05 ;{ }^{* *} p<0.01$.

\section{Discussion}

\subsection{Plant Height Is Closely Correlated with Yield in Rice}

Grain yield is determined by the plant biomass and harvest index. In the past century, substantial increases in rice yield have come from the progress of the chemical fertilizer industry, the "Green Revolution", and the application of hybrid rice [22]. For plant height, rice breeding projects have experienced three stages, such as dwarf $(70 \mathrm{~cm})$, semi-dwarf $(90 \mathrm{~cm})$, and semi-tall $(110 \mathrm{~cm})$. Breeders have nearly reached the acme of the mining-rice harvest index. Yuan Longping pointed out that increasing plant height appropriately is an effective strategy for high-yield rice breeding in the future [3]. One successful example is the application of IPA1, which showed large panicles, strong stems, and an enhanced plant height $[9,23]$. For instance, varieties harboring IPA1-2d [24] showed an approximately $15 \%$ increase in yield and plant heights of up to $120 \mathrm{~cm}$ (http:/ / www.ricedata.cn/variety/ index.htm, accessed on 13 January 2022). Hence, mapping of stable plant height QTLs is one of the most urgent tasks in high-yield rice breeding.

\subsection{RISLs with High-Throughput Map Ensure Precise QTL Mapping}

Compared with traditional genetic maps, a Bin map has the advantages of being high throughput, time saving, and labor saving. With 10 times the marker density of traditional maps, Bin maps can recognize recombination break points precisely and allow high-resolution QTL mapping [25,26]. For instance, a linkage map consisted of 1495 Bin markers was used to map the QTL plant height, and six QTLs were detected [25]. Interestingly, among these QTLs, $q P H 1$ and $q P H 3.1$ were co-located with mapped $q P H-1 b$ and $q P H-3 b$ in the present study, respectively. In our previous study, 386 RISLs were developed with a high-density genetic map of 3203 Bin markers, which guaranteed the reliability of our results [16]. It is noteworthy that 386 lines consisted of 193 pairs with two randomly selected individuals as a pair in the $\mathrm{F}_{7}$ progeny. Compared with RILs, the RISLs were efficient in both QTL mapping and validating. In the process of RISLs development, a library consisting of $1700 \mathrm{~F}_{11}, 2780 \mathrm{~F}_{12}$, and $2464 \mathrm{~F}_{13}$ lines were obtained for screening the RHLs for fine-mapping target QTLs. In the present study, $q P H-6$ was mapped into the interval of Bin1786-Bin1858 on chromosome $6 \mathrm{~L}$ in the $\mathrm{F}_{15}$ progeny, and the corresponding 
paired lines (Q13 and Q14) with minimal genomic differences except the target $q P H-6$ were selected by scanning corresponding $\mathrm{F}_{11}$ lines to obtain the candidate RHL (14Q13). Therefore, the RISL population is a powerful tool for QTL investigating.

\subsection{Stable QTLs for Plant Height in Nei2You No.6}

In the present study, in order to avoid deviation caused by environmental impact, phenotyping of RISLs was conducted from 2015 to 2018. A total of 19 QTLs were detected with a PVE in each QTL ranging from 2.08 to $14.05 \%$, indicating that the plant height of Nei2You No.6 was controlled by multiple medium/minor-effect QTLs (Figure 3, Tables 2 and 3). Noteworthy, six QTLs ( $q P H-1 a, q P H-1 b, q P H-2 b, q P H-3 b, q P H-6$, and $q P H-7 b)$ were detected repeatedly over four years and overlapped with the QTLs for plant height previously reported (Table 4), which also indicates the accuracy and stability of our mapping results. In detail, $q P H-1 b$ overlaps with $s d 1 / O s G A 20 o x 2$ [7], while $q P H-3 b$ co-located with OsGA20ox1 [8]. It is worth noting that $q P H-1 a, q P H-1 b, q P H-2 b, q P H-3 b$, and $q P H-7 b$ are co-located with the reported $Q P h 1, Q P h 1-2, Q P h 2, Q P h 3 a$, and $Q P h 7$ in the doubled-haploid population from IR64/Azucena, respectively [27]. Among the abovementioned six stable QTLs, $q P H-6$ could explain the 10.22-14.05\% of PVE with the largest effect over four years (Table 2), so we constructed a pair of NILs, $q P H 6-N$ and $q P H 6-R$, which harbored the $q P H-6$ allele from Nei2B and R8006, respectively. $q P H 6-R$ increased plant height by approximately $8 \mathrm{~cm}$ over $q P H 6-N$, resulting in an $18.50 \%$ increase in grain yield (Figure 4), suggesting that the $q P H-6$ allele of the restorer line (R8006) positively regulated plant height and grain yield. The interval of $q P H-6$ overlaps with the reported PH QTLs, such as $q P H-6-4$ [28], Ph6.1 [29], and Qph6 [30], indicating its stable existence. Innovatively, our study conducted the genetic dissection and phenotypic evaluation of $q P H-6$ for the first time. Considering that heading-stage genes may affect plant height, we compared the physical location of $q$ PH6 with the known heading-stage genes. In detail, there were four cloned QTLs for heading date on chromosome 6, such as Hd17, RFT1, Hd3a, and Hd1 [31-34], among which $H d 17, R F T 1$, and $H d 3 a$ were located on chromosome $6 \mathrm{~S}$, while $H d 1$ was on chromosome $6 \mathrm{~L}$. Because the physical positions of $q$ PH6 $(22.11 \mathrm{Mb}-29.41 \mathrm{Mb})$ near telomeres on chromosome $6 \mathrm{~L}$ are significantly different from $\mathrm{Hd} 1(9.3 \mathrm{Mb}$ on chromosome $6 \mathrm{~L})$, we believe that the candidate gene of $q P H 6$ is not a cloned heading gene. In summary, these results provide information of six stable QTLs for plant height, providing a basis for further mapping and molecular breeding to improve rice plant architecture.

Table 4. Comparison of stable quantitative trait loci (QTL) for plant height with previous studies.

\begin{tabular}{|c|c|c|c|c|}
\hline \multicolumn{2}{|c|}{ QTL of this Study } & \multirow[b]{2}{*}{ Published_Symbol } & \multicolumn{2}{|c|}{ Overlapped QTL Reported } \\
\hline QTL & Physical (Mb) & & Maker or Interval & Reference \\
\hline$q P H-1 a$ & $27.51-28.61$ & $Q P h 1$ & RG345-RG381 & [27] \\
\hline \multirow[t]{6}{*}{$q P H-1 b$} & $38.51-43.31$ & QTL on Chr.1 & $37.5-38.7 \mathrm{Mb}$ & [35] \\
\hline & & $q P H 1$ & RM7292-RM6696 & [36] \\
\hline & & QPh1-2 & RZ730-RG810 & [27] \\
\hline & & $\widetilde{q P H 1}$ & A187-A192 & [25] \\
\hline & & $q p h 1.1$ & RM102-RZ909 & [37] \\
\hline & & $s d 1$ & $38.38 \mathrm{Mb}$ & [7] \\
\hline$q P H-2 b$ & $34.01-36.81$ & $Q P h 2 a$ & RG95-RZ123 & [27] \\
\hline \multirow[t]{3}{*}{$q P H-3 b$} & $32.11-37.81$ & Qph3a & RG348-RZ329 & [27] \\
\hline & & qPH3.1 & C234-C247 & [25] \\
\hline & & OsGA20ox1 & $36.15 \mathrm{Mb}$ & [8] \\
\hline \multirow[t]{3}{*}{$q P H-6$} & $22.11-29.41$ & $q P H-6-4$ & RZ242-RZ342 & [28] \\
\hline & & Ph6.1 & RM162-RM30 & [29] \\
\hline & & Qph6 & HHU37-RZ682 & [30] \\
\hline \multirow[t]{2}{*}{$q P H-7 b$} & $4.98-6.81$ & QPh7 & RG511-RZ488 & [27] \\
\hline & & $q P H 7.1$ & ud7000260-7061293 & [38] \\
\hline
\end{tabular}




\section{Conclusions}

In four years, we located 19 medium/minor-effect QTLs for rice plant height in RISLs with high-throughput genetic mapping. Among these, six loci $(q P H-1 a, q P H-1 b$, $q P H-2 b, q P H-3 b, q P H-6$, and $q P H-7 b)$ showed stable effects over four years. With a PVE of $10.22-14.05 \%$ and additive effects of 3.45-4.63, the $q P H-6$ from R8006 can increase plant height by $10.70 \%$ and enhance grain yield by $18.50 \%$. With important agronomic traits, qPH-6 merits further examination. These QTLs for plant height provide important application value for molecular breeding in rice.

Author Contributions: Conceptualization, Y.Z. and W.W.; methodology, Y.Z. and M.Z.; supervision, Y.Z., W.W., L.C., S.C. and X.Z.; populations construction, Y.Z. and M.Z.; data collection and analysis, H.Y., Q.Y., Y.Z. and Y.K.; writing-review and editing, H.Y., Y.Z., Q.Y. All authors have read and agreed to the published version of the manuscript.

Funding: This research was supported by the Fundamental Research Funds of Central Public Welfare Research Institutions (CPSIBRF-CNRRI-202102), the China National Agricultural Rice IndustryTechnology System (CARS-01-03), and the Chinese Academy of Agricultural Sciences Innovation Project (CAAS-ASTIP-2013-CNRRI).

Institutional Review Board Statement: Not applicable.

Data Availability Statement: The datasets used or analyzed in the present study are available upon demand from the corresponding author.

Conflicts of Interest: The authors declare no conflict of interest.

\section{References}

1. Zhang, Q.F. Strategies for developing Green Super Rice. Proc. Natl. Acad. Sci. USA 2007, 104, 16402-16409. [CrossRef] [PubMed]

2. Yuan, L.P. Hybrid Rice Science; China Agriculture Press: Beijing, China, 2002.

3. Yuan, L.P. Conceiving of breeding further super-high-yield hybrid rice. Hybrid Rice 2012, 27, 1-8. (In Chinese)

4. Mooney, B.P. The second green revolution? Production of plant-based biodegradable plastics. Biochem. J. 2009, 418, $219-232$. [CrossRef] [PubMed]

5. Cao, G.; Zhu, J.; He, C.; Gao, Y.; Yan, J.; Wu, P. Impact of epistasis and QTL $\times$ environment interaction on the developmental behavior of plant height in rice (Oryza sativa L.). Theor. Appl. Genet. 2001, 103, 153160. [CrossRef]

6. $\quad$ Peng, J.; Richards, D.E.; Hartley, N.M.; Murphy, G.P.; Devos, K.M.; Flintham, J.E.; Beales, J.; Fish, L.J.; Worland, A.J.; Pelica, F.; et al. 'Green revolution' genes encode mutant gibberellin response modulators. Nature 1999, 400, 256-261. [CrossRef]

7. Sasaki, A.; Ashikari, M.; Ueguchi-Tanaka, M.; Itoh, H.; Nishimura, A.; Swapan, D.; Ishiyama, K.; Saito, T.; Kobayashi, M.; Khush, G.S.; et al. Green revolution: A mutant gibberellin-synthesis gene in rice. Nature 2002, 416, 701-702. [CrossRef]

8. Oikawa, T.; Koshioka, M.; Kojima, K.; Yoshida, H.; Kawata, M. A role of OsGA20ox1, encoding an isoform of gibberellin 20-oxidase, for regulation of plant stature in rice. Plant Mol. Biol. 2004, 55, 687-700. [CrossRef]

9. Jiao, Y.; Wang, Y.; Xue, D.; Wang, J.; Yan, M.; Liu, G.; Dong, G.; Zeng, D.; Lu, Z.; Zhu, X.; et al. Regulation of OsSPL14 by OsmiR156 defines ideal plant architecture in rice. Nat. Genet. 2010, 42, 541-544. [CrossRef]

10. Springer, N. Shaping a better rice plant. Nat. Genet. 2010, 42, 475-476. [CrossRef]

11. Xue, W.Y.; Xing, Y.Z.; Weng, X.Y.; Zhao, Y.; Tang, W.J.; Wang, L.; Zhou, H.G.; Yu, S.B.; Xu, C.G.; Li, X.H.; et al. Natural variation in Ghd7 is an important regulator of heading date and yield potential in rice. Nat. Genet. 2008, 40, 761-767. [CrossRef]

12. Yan, W.; Liu, H.; Zhou, X.; Li, Q.; Zhang, J.; Lu, L.; Liu, T.; Liu, H.; Zhang, C.; Zhang, Z.; et al. Natural variation in Ghd7.1 plays an important role in grain yield and adaptation in rice. Cell Res. 2013, 23, 969-971. [CrossRef] [PubMed]

13. Wei, X.J.; Xu, J.F.; Guo, H.N.; Jiang, L.; Chen, S.H.; Yu, C.Y.; Zhou, Z.L.; Hu, P.S.; Zhai, H.Q.; Wan, J.M. DTH8 suppresses flowering in rice, influencing plant height and yield potential simultaneously. Plant Physiol. 2010, 153, 1747-1758. [CrossRef] [PubMed]

14. Liu, J.H.; Shen, J.Q.; Xu, Y.; Li, X.H.; Xiao, J.H.; Xiong, L.Z. Ghd2, a CONSTANS-like gene, confers drought sensitivity through regulation of senescence in rice. J. Exp. Bot. 2016, 67, 5785-5798. [CrossRef] [PubMed]

15. Xu, J.; Shang, L.; Wang, J.; Chen, M.; Fu, X.; He, H.; Wang, Z.; Zeng, D.; Zhu, L.; Hu, J.; et al. The SEEDLING BIOMASS 1 allele from indica rice enhances yield performance under low-nitrogen environments. Plant Biotechnol. J. 2021, 19, 1681-1683. [CrossRef] [PubMed]

16. Zhang, M.; Zhou, Z.P.; Chen, Y.Y.; Cao, Y.R.; Deng, C.W.; Xue, P.; Zhan, X.D.; Cheng, S.H.; Cao, L.Y.; Zhang, Y.X. Finding new addictive QTL for yield traits based on a high-density genetic map in hybrid rice. Plant Growth Regul. 2020, 93, 105-115. [CrossRef]

17. Wang, S.; Basten, C.J.; Zeng, Z.B. Windows QTL Cartographer 2.5; Department of Statistics, North Carolina State University: Raleigh, NC, USA, 2012; Available online: https:/ / statgen.ncsu.edu/qtlcart/WQTLCart.htm (accessed on 13 January 2022).

18. Zhang, H.W.; Fan, Y.Y.; Zhu, Y.J.; Chen, J.Y.; Yu, S.B.; Zhuang, J.Y. Dissection of the qTGW1.1 region into two tightly-linked minor QTLs having stable effects for grain weight in rice. BMC Genet. 2016, 17, 98. [CrossRef] [PubMed] 
19. Wang, Z.; Chen, J.Y.; Zhu, Y.J.; Fan, Y.Y.; Zhuang, J.Y. Validation of $q$ GS10, a quantitative trait locus for grain size on the long arm of chromosome 10 in rice (Oryza sativa L.). J. Integr. Agric. 2017, 16, 16-26. [CrossRef]

20. McCouch, S.R.; CGSNL. Gene nomenclature system for rice. Rice 2008, 1, 72-84. [CrossRef]

21. Orjuela, J.; Garavito, A.; Bouniol, M.; Arbelaez, J.D.; Moreno, L.; Kimball, J.; Wilson, G.; Rami, J.F.; Tohme, J.; McCouch, S.R.; et al. A universal core genetic map for rice. Theor. Appl. Genet. 2009, 120, 563-572. [CrossRef]

22. Meng, T.; Ge, J.; Zhang, X.; Chen, X.; Zhou, G.; Wei, H. Improvements in Plant Morphology Facilitating Progressive Yield Increases of japonica Inbred Rice since the 1980s in East China. Agriculture 2021, 11, 834. [CrossRef]

23. Lu, Z.; Yu, H.; Xiong, G.; Wang, J.; Jiao, Y.; Liu, G.; Jing, Y.; Meng, X.; Hu, X.; Qian, Q.; et al. Genome-wide binding analysis of the transcription activator ideal plant architecture1 reveals a complex network regulating rice plant architecture. Plant Cell 2013, 25, 3743-3759. [CrossRef] [PubMed]

24. Zhang, L.; Yu, H.; Ma, B.; Liu, G.F.; Wang, J.J.; Wang, J.M.; Gao, R.C.; Li, J.J.; Liu, J.Y.; Xu, J.; et al. A natural tandem array alleviates epigenetic repression of IPA1 and leads to superior yielding rice. Nat. Commun. 2017, 8, 14789. [CrossRef] [PubMed]

25. Han, Z.; Hu, W.; Tan, C.; Xing, Y. QTLs for heading date and plant height under multiple environments in rice. Genetica 2017, 145, 67-77. [CrossRef] [PubMed]

26. Zhu, M.; Liu, D.; Liu, W.; Li, D.; Liao, Y.; Li, J.; Fu, C.; Fu, F.; Huang, H.; Zeng, X.; et al. QTL mapping using an ultra-high-density SNP map reveals a major locus for grain yield in an elite rice restorer R998. Sci. Rep. 2017, 7, 10914. [CrossRef]

27. Li, Z.K.; Yu, S.B.; Lafitte, H.R.; Huang, N.; Courtois, B.; Hittalmani, S.; Vijayakumar, C.H.; Liu, G.F.; Wang, G.C.; Shashidhar, H.E.; et al. QTL x environment interactions in rice. I. heading date and plant height. Theor. Appl. Genet. 2003, 108, 141-153. [CrossRef]

28. Guohua, Y.; Shaoqing, L.; Jingzhen, D.; Bing, Y.; Kai, D.; Yangsheng, L.; Yingguo, Z. Molecular dissection of developmental behavior of tiller number and plant height and their relationship in rice (Oryza sativa L.). Hereditas 2006, 143, $236-245$.

29. Thomson, M.J.; Tai, T.H.; McClung, A.M.; Lai, X.H.; Hinga, M.E.; Lobos, K.B.; Xu, Y.; Martinez, C.P.; McCouch, S.R. Mapping quantitative trait loci for yield, yield components and morphological traits in an advanced backcross population between Oryza rufipogon and the Oryza sativa cultivar Jefferson. Theor. Appl. Genet. 2003, 107, 479-493. [CrossRef]

30. Mei, H.W.; Luo, L.J.; Ying, C.S.; Wang, Y.P.; Yu, X.Q.; Guo, L.B.; Paterson, A.H.; Li, Z.K. Gene actions of QTLs affecting several agronomic traits resolved in a recombinant inbred rice population and two testcross populations. Theor. Appl. Genet. 2003, 107, 89-101. [CrossRef]

31. Yuan, Q.; Saito, H.; Okumoto, Y.; Inoue, H.; Nishida, H.; Tsukiyama, T.; Teraishi, M.; Tanisaka, T. Identification of a novel gene ef7 conferring an extremely long basic vegetative growth phase in rice. Theor. Appl. Genet. 2009, 119, 675-684. [CrossRef]

32. Komiya, R.; Ikegami, A.; Tamaki, S.; Yokoi, S.; Shimamoto, K. Hd3a and RFT1 are essential for flowering in rice. Development 2008, 135, 767-774. [CrossRef]

33. Monna, L.; Lin, X.; Kojima, S.; Sasaki, T.; Yano, M. Genetic dissection of a genomic region for a quantitative trait locus, Hd3, into two loci, Hd3a and Hd3b, controlling heading date in rice. Theor. Appl. Genet. 2002, 104, 772-778. [CrossRef] [PubMed]

34. Yamamoto, T.; Kuboki, Y.; Lin, S.Y.; Sasaki, T.; Yano, M. Fine mapping of quantitative trait loci hd-1, hd-2 and hd-3, controlling heading date of rice, as single mendelian factors. Theor. Appl. Genet. 1998, 97, 37-44. [CrossRef]

35. Shearman, J.R.; Vejchasarn, P.; Naktang, C.; Phansenee, Y.; Jomchai, N.; Lanceras-Siangliw, J.; Tangphatsornruang, S.; Toojinda, T. Rice height QTLs in KDML105 chromosome segment substitution lines. Genomics 2019, 114, 482-487. [CrossRef] [PubMed]

36. Ma, F.Y.; Du, J.; Wang, D.C.; Wang, H.; Zhao, B.B.; He, G.H.; Yang, Z.L.; Zhang, T.; Wu, R.H.; Zhao, F.M. Identification of long-grain chromosome segment substitution line Z744 and QTL analysis for agronomic traits in rice. J. Integr. Agric. 2020, 19, 1163-1169. [CrossRef]

37. Lanceras, J.C.; Pantuwan, G.; Jongdee, B.; Toojinda, T. Quantitative trait loci associated with drought tolerance at reproductive stage in rice. Plant Physiol. 2004, 135, 384-399. [CrossRef]

38. Descalsota-Empleo, G.I.; Amparado, A.; Inabangan-Asilo, M.A.; Tesoro, F.; Stangoulis, J.; Reinke, R.; Swamy, B.P.M. Genetic mapping of QTL for agronomic traits and grain mineral elements in rice. Crop J. 2019, 7, 560-572. [CrossRef] 